\title{
DEFINING CANCER SURVIVOR AND CANCER SURVIVORSHIP: THE WHO, WHAT, AND WHEN
}

\author{
DEFINING CANCER SURVIVOR AND CANCER SURVIVORSHIP: THE WHO, WHAT, \\ AND WHEN
}

\author{
Samantha L. Wronski \\ Uniformed Services University of the Health Sciences, Medical and Clinical Psychology, Bethesda, Maryland, \\ United States of America.
}

\section{Abstract}

Over the past three decades various definitions of cancer survivor and cancer survivorship have been proposed. These definitions frequently describe (1) who is considered a cancer survivor and who is experiencing cancer survivorship, (2) what it means to a be survivor and experience survivorship, and (3) when someone is considered a survivor and when survivorship begins. Descriptive epidemiology indicates that certain individuals diagnosed and treated for cancer describe the presence of specific unmet needs following diagnosis and treatment for cancer. Evidence also points to an increased likelihood of cancer recurrence or a new cancer in many cancer patients. These observations should be reflected in the case definitions of cancer survivor and cancer survivorship. This paper reviews the literature for evidence to validate existing definitions of cancer survivor and cancer survivorship and proposes updated definitions for each. Based on this evidence, a cancer survivor is defined as an individual diagnosed with cancer. The period following primary treatment, which is characterized by transitions in care and a need to address the late effects of cancer and its treatment, may be a particularly critical time for the cancer survivor. The definition does not preclude the major involvement of family, friends, caregivers, and providers, but does place the focus on the individual who received the diagnosis
Resumen

Durante las últimas tres décadas se han propuesto diversas definiciones del superviviente de cáncer y la supervivencia del cáncer. Estas definiciones describen con frecuencia (1) quién se considera un superviviente de cáncer y quién experimenta la supervivencia del cáncer, (2) lo que significa ser superviviente y la experiencia de sobrevivir, y (3) cuándo se considera que alguien es un superviviente y cuándo comienza a ser un superviviente. La epidemiología descriptiva indica que ciertos individuos diagnosticados y tratados de cáncer describen la presencia de necesidades específicas insatisfechas tras el diagnóstico y tratamiento para el cáncer. Los datos disponibles. apuntan a un aumento de la probabilidad de recurrencia del cáncer o un nuevo cáncer en muchos pacientes con cáncer. Estas observaciones deben reflejarse en las definiciones de caso del superviviente de cáncer y la supervivencia del cáncer. Este artículo revisa los datos relativos a la validez de las definiciones existentes de superviviente de cáncer y supervivencia del cáncer y propone definiciones actualizadas para cada uno. Con base en estos hallazgos, se define como superviviente de cáncer a un individuo diagnosticado con cáncer. El periodo que sigue al tratamiento primario, que se caracteriza por las transiciones en el cuidado y la necesidad de abordar los efectos tardíos del cáncer y su tratamiento, puede ser un momen-

Correspondencia:

Samantha L. Wronski, BS (Hons),

Department of Medical and Clinical Psychology, Uniformed Services University,

4301 Jones Bridge Road, Bethesda, MD 20814,

E-mail: samantha.wronski@usuhs.edu.

The opinions and assertions contained herein are the private views of the authors and are not to be construed as being official or as reflecting the views of the Uniformed Services University of the Health Sciences or the Department of Defense. 
of cancer. Children and young adult cancer survivors should be housed in subgroups under the "cancer survivor" umbrella. In addition, cancer survivorship is defined as the period of time beginning at cancer diagnosis where attention by the survivor and his or her care team is directed at addressing needs related to health, symptoms, function, lifestyle, and well-being; these needs may change through the care trajectory. Coordination of care between oncologist specialists involved in the early phases of cancer diagnosis and treatment and primary care physicians involved in longterm follow-up is critical. As new knowledge is acquired regarding cancer survival and the cancer experience, modifications to these proposed definitions will be imperative.

Keywords: Cancer, oncology, cancer survivor, cancer survivors, cancer survivorship, definition, definitions. to especialmente crítico para el superviviente de cáncer. La definición no excluye la importante participación de la familia, amigos, cuidadores y proveedores, pero pone el foco en la persona que recibió el diagnóstico de cáncer. Los niños y los jóvenes adultos supervivientes de cáncer deben ser ubicados en subgrupos bajo el paraguas de "superviviente de cáncer". Además, definimos la supervivencia del cáncer como el período de tiempo que comienza en el diagnóstico del cáncer en el que la atención del equipo de cuidados para el superviviente se centra en las necesidades relativas a la salud, la funcionalidad, los síntomas, el estilo de vida y bienestar; estas necesidades pueden cambiar a través de la trayectoria del cuidado. Es fundamental la coordinación de la atención entre los especialistas oncólogos, que participan en las primeras fases de diagnóstico y tratamiento del cáncer, y los médicos de atención primaria involucrados en el seguimiento a largo plazo de la enfermedad. Las modificaciones a las definiciones propuestas se harán necesarias a medida que se adquieran nuevos conocimientos en relación a la supervivencia del cáncer y la experiencia del cáncer.

Palabras clave: Cáncer, oncología, superviviente de cáncer, supervivientes de cáncer, supervivencia al cáncer, definiciones.

\section{OVERVIEW}

While the incidence of cancer continues to increase, improvements in detection, diagnosis, and treatment ${ }^{(1)}$ have led to steady declines in mortality over the past four decades $^{(2)}$. Internationally, an estimated 32.6 million cancer survivors were living within five years of diagnosis in $2012^{(2)}$. This statistic is based exclusively on a definition of cancer survivor that only considers 5-year prevalent cancer cases. However, other definitions of "cancer survivor" have been considered over the past several decades ${ }^{(3)}$. There is also a lack of consensus surrounding the definition of "cancer survivorship," a term often used in tandem with "cancer survivor." Though authors of recent reviews have provided excellent summaries on key concepts related to cancer survivors and cancer survivorship ${ }^{(3,4)}$, they have not clearly proposed updated definitions of cancer survivor and cancer survivorship based on the literature. In order to move forward in our understanding and ability to determine meaningful intervention targets and outcomes for cancer survivorship care, global consensus should be reached regarding evidence-based definitions of cancer survivor and cancer survivorship. As the definitions will guide resource allocation, it will be important that they capture the subset of individuals most affected by cancer and its treatment.

Tables 1 and 2 provide the range of definitions for cancer survivor and cancer survivorship that have been proposed over the last three decades. These definitions 
seek to answer the following common questions: (1) Who is a cancer survivor and who is included in the cancer survivorship experience?; (2) What does it mean to be a survivor and experience survivorship?; and (3) When is someone considered a survivor and when does survivorship begin? This paper will provide a literature review of evidence related to each of these questions and propose updated definitions for cancer survivor and cancer survivorship based on these findings.

\section{Who is a cancer survivor and who is included in the cancer survivorship experience?}

The scope of the population included as cancer survivors and those experiencing cancer survivorship has implications for who should be included in cancer survivorship care, and, by extension, who should be targeted for cancer survivorship research. Definitions of cancer survivorship such as that from the National Cancer In-

\section{Table 1. Cancer Survivor: Definitions}

\begin{tabular}{|c|c|c|}
\hline Source & Term Defined & Definition \\
\hline $\begin{array}{l}\text { Historical Definition (Leigh, } \\
\text { 1996) }\end{array}$ & Cancer Survivor & $\begin{array}{l}\text { Family members who survived the loss of } \\
\text { a loved one to cancer. }\end{array}$ \\
\hline $\begin{array}{l}\text { Centers for Disease Control and } \\
\text { Prevention (Division of Cancer } \\
\text { Prevention and Control, 2014) }\end{array}$ & Cancer Survivor & $\begin{array}{l}\text { Anyone who has been diagnosed with } \\
\text { cancer, from the time of diagnosis through } \\
\text { the balance of his or her life. }\end{array}$ \\
\hline $\begin{array}{l}\text { Biomedical Definition (Leigh, } \\
\text { 1996; Marcus, 2004; Rowland, } \\
\text { 2007; Twombly, 2004) }\end{array}$ & Survivor & $\begin{array}{l}\text { Individuals who have had a life- } \\
\text { threatening disease but have remained } \\
\text { disease free for a minimum of } 5 \text { years. }\end{array}$ \\
\hline $\begin{array}{l}\text { World Health Organization } \\
\text { (World Health Organization, } \\
\text { 2008)(10) }\end{array}$ & Cancer Survivors & $\begin{array}{l}\text { Those patients who having had cancer, } \\
\text { are, following treatment, now cured } \\
\text { of the disease. Cure is defined as the } \\
\text { attainment of normal life expectancy } \\
\text { and has three important components: } \\
\text { (1) recovery from all evidence of disease } \\
\text { (complete remission); (2) attainment of a } \\
\text { stage of minimal or no risk of recurrence } \\
\text { or relapse; (3) restoration of functional } \\
\text { health (physical, developmental, and } \\
\text { psychosocial). }\end{array}$ \\
\hline $\begin{array}{l}\text { Journal of Cancer Survivorship } \\
\text { (Feuerstein, 2007) }^{(11)}\end{array}$ & Cancer Survivors & $\begin{array}{l}\text { Populations and individuals with a } \\
\text { diagnosis of cancer who have completed } \\
\text { primary treatment or the major aspects } \\
\text { of treatment for cancer. Survivors may } \\
\text { be continuing with "treatment" or } \\
\text { management such that it is unclear when } \\
\text { primary treatment has ended. Survivors } \\
\text { will also have a desire or need to "get on } \\
\text { with their lives." Survivors are considered } \\
\text { individuals with the cancer diagnosis, not } \\
\text { the family. }\end{array}$ \\
\hline
\end{tabular}




\begin{tabular}{|c|c|c|c|c|c|c|c|c|c|}
\hline & 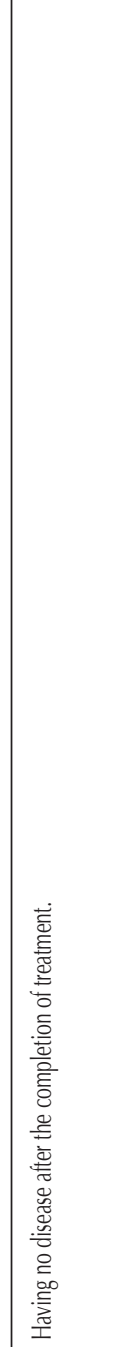 & 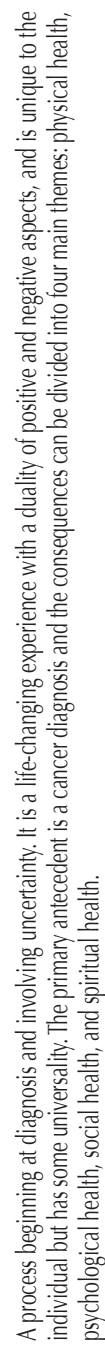 & 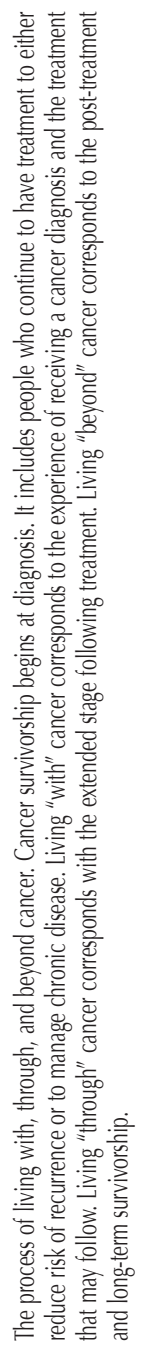 & 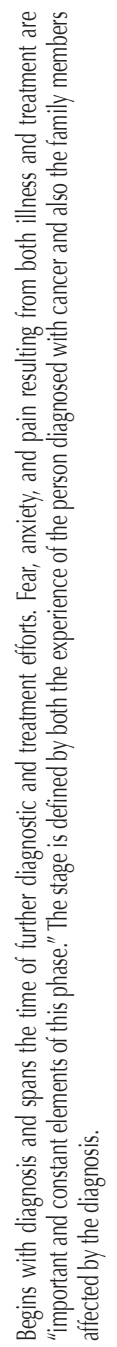 & 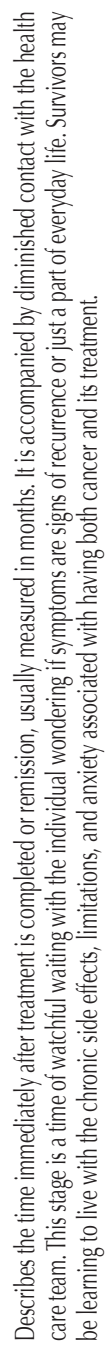 & 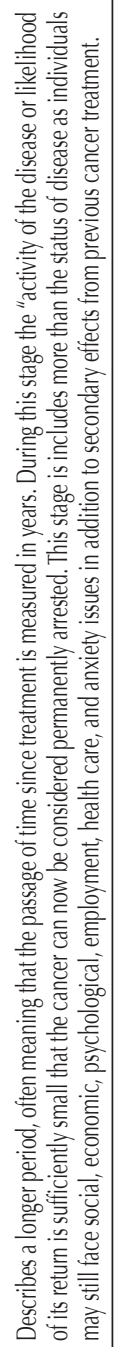 & 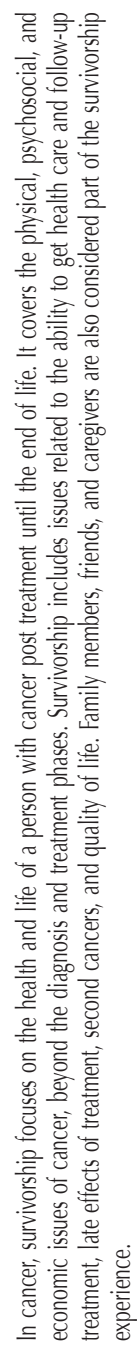 & 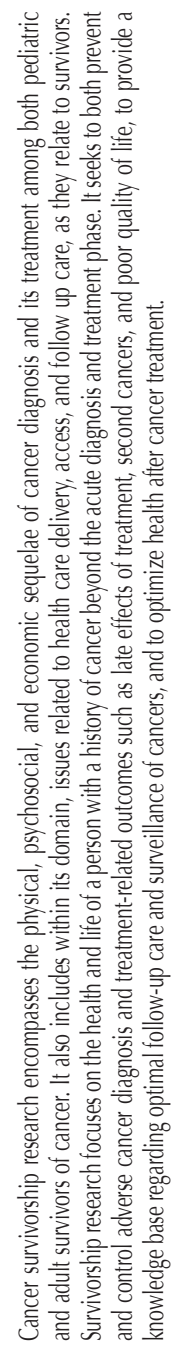 & 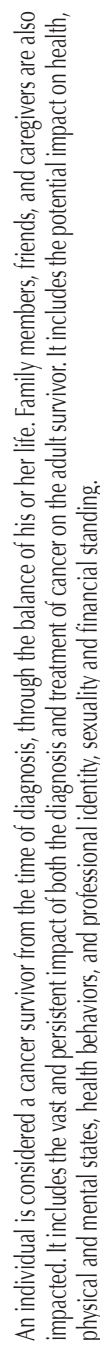 \\
\hline 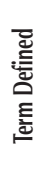 & 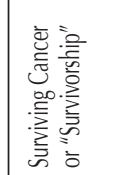 & 总 & 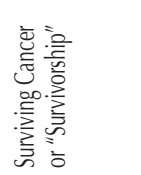 & 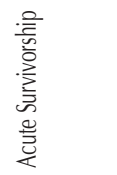 & 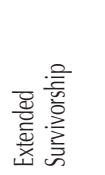 & 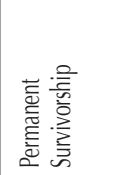 & 产 & 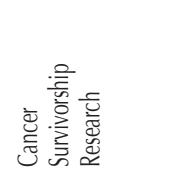 & 瓷 \\
\hline 总 & 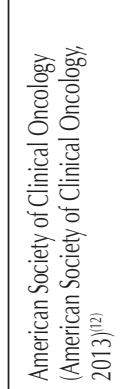 & 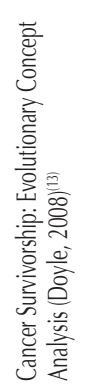 & 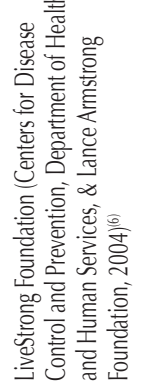 & 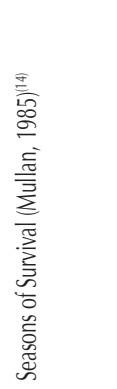 & 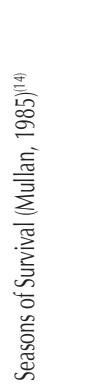 & 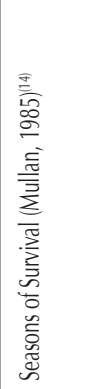 & 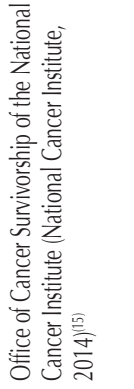 & 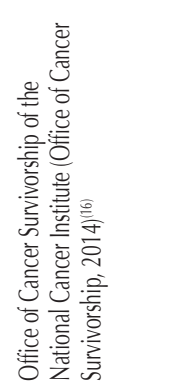 & 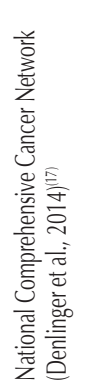 \\
\hline
\end{tabular}


stitute $(\mathrm{NCl})^{(15)}$, include "family members, friends, and caregivers" (See Table 2). A recent definition by $\mathrm{NCl}$ of cancer survivorship research directs efforts to the individual who received the cancer diagnosis and treatment. $\mathrm{NCl}$ proposes that research in the area of cancer survivorship "focus on the health and life of a person with a history of cancer beyond the acute diagnosis and treatment phase" ${ }^{\prime \prime(16)}$ and does not mention family members, friends, or caregivers (See Table 2).

However, there is evidence to suggest that psychosocial interventions including family members or caregivers are more efficacious than interventions focusing solely on patients with chronic illness ${ }^{(18)}$. The patients in these interventions are not unlike cancer patients, who are increasingly being conceptualized as having a chronic illness. A meta-analysis of randomized trials compared usual medical care to chronic illness psychosocial interventions targeting either a patient's closest family member or both the patient and the family member ${ }^{(19)}$. The authors found that including a spouse in interventions decreased depression and mortality in patients, and caregiving burden, depression and anxiety in family members ${ }^{(19)}$. Family interventions have shown promise specifically in cancer patients in reducing patient feelings of hopelessness and negative appraisal of illness, as well as reducing negative appraisal of caregiving ${ }^{(20)}$.

While family members, friends, and caregivers may impact a cancer survivor's experience in terms of symptom burden and outcomes, other parties, such as clinicians, may do the same. The type and quality of clinicians serving cancer patients has been found to influence important aspects of survivorship including satisfaction, symptom control, inpatient hospital days, cost, and pain severity ${ }^{(21,22)}$. The $\mathrm{NCl}$ definition of cancer survivorship acknowledges the impact of clinicians by stating that cancer survivorship "includes issues related to the ability to get health care and follow-up treatment"(15), yet clinicians are not specifically included in the definition of cancer survivorship. Thus, whether or not a given party is "part of the survivorship experience" may not be sufficient to include that party in the definitions of cancer survivor and cancer survivorship. Rather, whether or not a given party (in this case, family, friends, or caregivers) shares the same experience as the cancer survivor should ultimately guide the appropriateness of their inclusion in definitions of cancer survivor and cancer survivorship.

At a basic level, it is not hard to argue that family members, friends, and caregivers are exempt from the numerous medical treatments and tests that cancer survivors often undergo. Further, while the experience of family, friends, and caregivers includes the threat of loss, the experience of cancer survivors includes the more personal threat of death. When it comes to subjective illness experiences, caregivers and cancer patients have different perceptions of psychological symptoms ${ }^{(23)}$, marriage quality, and aspects of patient functioning (e.g. depression, fear of the future, and confidence in treatment ${ }^{(24)}$. Compared to their caregiver's report, patients would view their functioning more positively and their marital quality more negatively ${ }^{(24)}$. Consequently, it seems reasonable to conclude that the experience of cancer survivorship is exclusive and unique to the cancer patient, who alone can be considered a cancer survivor. Clinicians and researchers should not, however, dismiss the important role that family members, friends, and caregivers can play in a cancer patient's experience as well as the unique challenges they face as a consequence of having a loved one battle cancer.

Additional debate involves whether both adults and children should be included in a universal definition of cancer survivor. There is a paucity of literature di- 
rectly comparing the experiences of childhood cancer survivors to adult cancer survivors. One study found that significantly more adult, but not child, cancer survivors scored in the clinical range for depression (29\% vs. $18 \%$, respectively) and somatic problems $(23 \% \text { vs. } 12 \% \text { respectively })^{(25)}$. No significant correlation was found between time elapsed from cancer diagnosis to completion of the questionnaires with any of the psychosocial measures ${ }^{(25)}$. With childhood survivors constituting a minority $0.5 \%$ to $3.0 \%$ of the total survivor population $^{(26,27)}$, this subgroup could arguably still be considered a part of "cancer survivors," even if they experience a different set of challenges from adult cancer survivors.

Nevertheless, it should be noted that separate survivorship guidelines have been developed for the care of childhood cancer survivors $^{(28)}$ and adult cancer survivors ${ }^{(17)}$. While both children and adults who receive a cancer diagnosis and experience long term and late effects of diagnosis and treatment can be considered cancer survivors, both groups are frequently treated as distinct subgroups, often with unique survivorship needs. Future research should explore the similarities and differences among children, young adult, and adult cancer survivors in order to clarify which problems and associated interventions may be generalizable and which may require adaptations. This paper will only focus on adult and young adult cancer survivors and survivorship. The U.S. adult cancer survivor population consists of individuals aged 15 years and older ${ }^{(29)}$, which includes the subset of adolescents and young adult cancer survivors ranging from 15 to 39 years at diagnosis ${ }^{(30)}$.

\section{What does it mean to be a survivor and experience survivorship?}

Cancer survivors report being in good health, having a good to excellent quality of life $\mathrm{e}^{(31,32)}$, and not suffering from psychological morbidity or experiencing a large number of unmet supportive care needs ${ }^{(33)}$. However, a proportion of those living after diagnosis and primary treatment do continue to experience the burden of physical and psychosocial health problems related to cancer and its treatment ${ }^{(34)}$. A population-based study comparing individuals who completed primary treatment for cancer to individuals with non-cancer chronic illnesses and healthy controls observed that those with cancer experienced the poorest health on all indicators studied ${ }^{(35)}$. This study clearly indicates that individuals following diagnosis and treatment for cancer report a number of problem areas that differ from what has been observed in other chronic illnesses. A review of longterm and late effects of a range of treatment exposures in individuals following cancer treatment reported that these problems may last for more than 10 years $^{(36)}$.

A definition of cancer survivor provided by the World Health Organization (WHO) (See Table 1) ${ }^{(10)}$ assumes that individuals are cancer survivors if they meet the following three criteria: 1) "recovery from all evidence of disease," 2) "attainment of a stage of minimal or no risk of recurrence or relapse," and 3) "restoration of functional health (physical, developmental, and psy-

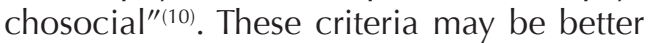
viewed as suitable and well-intentioned goals, given the aforementioned evidence pointing to frequent and persistent secondary health and functional effects long after an individual's cancer diagnosis and treatment.

A major concern with the cancer survivor definition from $\mathrm{WHO}$ and similar definitions $^{(12)}$ is their inconsistency with the evidence that many post-treatment cancer patients continue to carry a significant risk of recurrence or relapse for the remainder of their lives ${ }^{(37)}$. This risk varies depending on the type of initial primary 
cancer diagnosed, treatment received, and age at diagnosis ${ }^{(38,39)}$. The American Cancer Society (ACS) found that following primary treatment for cancer, patients of all cancer diagnoses have a $15 \%$ lifetime risk of developing a second primary cancer $^{(38)}$. Survivors of certain cancers face a considerable threat of recurrence. In bladder cancer patients, for instance, the rate of recurrence, ranges from $15-61 \%$ within 1 year and from $31-78 \%$ within 5 years ${ }^{(40)}$. In one of the most common cancers ${ }^{(38)}$, colorectal cancer (CRC), recurrence ranges from $12 \%$ within 5 years for stage I patients ${ }^{(41)}$ to $40 \%$ for stage II or III patients ${ }^{(42)}$. In $20 \%$ of female breast cancer cases, local, regional or distant recurrence occurs within 10 years after cancer diagnosis ${ }^{(42)}$. For prostate cancer, an average of $15 \%$ of patients experience recurrence within 5 years of radical prostatectomy $^{(44)}$.

Even within patients of a single cancer type, survival and recurrence has great variation. Also, limiting the case definition of a cancer survivor and the period of cancer survivorship to only those individuals with minimal or no risk of recurrence or relapse requires valid models for prognostic scoring to predict recurrence. In some cancers, such as gastric cancer, models have been developed with high levels of sensitivity and specificity in predicting recurrence ${ }^{(45)}$. However, in many other cancers, predicting prognosis remains clinically challenging $^{(46-49)}$. Even when risk prediction models exist, communicating survival probabilities to patients is often laden with difficulties (e.g., reports are too difficult for patients to understand, graphs are overly technical, and recurrence probabilities with and without therapy can divert patients from considering adverse effects a part of the trade-off), and may backfire or cause confusion $^{(50)}$. Given that both secondary health and functional problems and a risk of recurrence can often occur among individuals following diagnosis and primary cancer treatment, it follows that the definitions of cancer survivor and cancer survivorship should avoid excluding individuals on the basis of susceptibility to these experiences.

\section{When is someone considered a survivor and when does survivorship begin?}

The classic definition of cancer survivorship was first proposed by Dr. Fitzhugh Mullan three decades ago ${ }^{(14)}$. This definition, which includes three "seasons of survival" (See Table 2), considers cancer patients to be survivors from the time of diagnosis. Post-diagnosis, Mullan argued, was the time when cancer patients naturally fell into the category of "survivor" by being frequently confronted with their own mortality and needing to make changes that could impact their future.

Cancer patients experience unique concerns related to their cancer at each stage of the care trajectory. At diagnosis, some may face an "existential crisis"; when primary treatment has ended, individuals may experience other long-term concerns (e.g., health, receipt of quality health care following treatment, functional changes, lifestyle changes ${ }^{(51)}$. Ability to work also changes throughout the trajectory, with the majority of cancer patients who worked before their diagnosis being able to return following treatment ${ }^{(4,51)}$. At all of these points, cancer patients need to "survive" and "thrive" through each of the (often changing) issues confronting them.

As such, the proposed definitions of cancer survivor and cancer survivorship should include individuals immediately following a cancer diagnosis. Consistent with several existing definitions ${ }^{(6,13-17)}$, the view that survivorship begins from the moment of diagnosis is becoming increasingly prevalent ${ }^{(51)}$. By contrast, several definitions of cancer survivor and survivorship require completion of primary treatment, which may vary across cancer 
types and, in some cases, be difficult to define. As diagnosis is a universal concept across cancer survivors, it is a time point that naturally yields itself to universal definitions of cancer survivor and cancer survivorship.

Proposing that survivorship begins at diagnosis does not preclude the emphasis that should be placed on the period following cancer treatment. Despite problems regularly faced by cancer patients following treatment ${ }^{(35)}$, they often transition into a phase including isolation and less involvement from their medical team $^{(4)}$. Among patients $(30 \%)$ who report five or more unmet needs at the end of treatment, $60 \%$ said that those needs were still unmet at six months ${ }^{(52)}$. This may point to a need for more care in the posttreatment stage.

However, a lack of care is routinely due to a lack of clarity among patients, oncologists, and primary care physicians (PCPs) about who is responsible for providing care for long-term cancer survivors ${ }^{(53)}$. A survey of oncologists, who typically are most involved during diagnosis and treatment, and PCPs, who are often most involved in follow-up care, found that both expected to be significantly involved in cancer survivorship care ${ }^{(53)}$. Defining survivorship as beginning at diagnosis underscores the importance of a shared responsibility among early treatment-stage clinicians and follow-up stage clinicians in addressing survivorship issues. It is also consistent with the Institute of Medicine's four essential components of survivorship care: prevention, surveillance, intervention, and coordination ${ }^{(51)}$. Continued care by both oncologist specialists and PCPs results in patients receiving more follow-up cancer and noncancer preventive services than care by an oncologist specialist or PCP alone ${ }^{(54)}$. Improved communication about long-term care expectations from clinicians during treatment may aid in pre- venting misunderstandings among cancer patients and help them to better navigate the health care system during follow-up. Multidisciplinary and integrated clinics ${ }^{(4)}$ are two models of survivorship care which may help to create a sense of shared responsibility for the cancer survivor and improve access to clinicians best equipped to address the changing needs of cancer patients through the different stages of survivorship.

\section{PROPOSED WORKING DEFINITIONS}

\section{Cancer survivor}

A cancer survivor is any individual who is living and diagnosed with some type of cancer. By extension, cancer survivors are populations of individuals diagnosed and living with any type of cancer. Cancer survivors are individuals who possess the unique direct experience of going through cancer, and not their family members, friends, or caregivers. The identity of "cancer survivor" is maintained from diagnosis, through treatment, post-treatment, and for the remainder of the individual's life. The "cancer survivor" identity may be particularly salient after individuals have completed primary cancer treatment or recognizing that for some individuals, this stage will not have a clear ending - the major aspects of cancer treatment. The definition is not contingent on the cancer being cured. It does not assume that absence of disease is necessary or sufficient. Children and young adult cancer survivors should be housed in subgroups under the "cancer survivor" umbrella. As Table 1 indicates, this case definition is more restrictive than earlier definitions that included members of the family or friends, but it is more inclusive in terms of not requiring "cure" or a particular time period to have passed in order to be considered a cancer survivor. 


\section{Cancer survivorship}

Cancer survivorship is the period of time beginning at cancer diagnosis and spanning through treatment, post-treatment, and the remainder of the individual's life. The period following major primary treatments may be of particular salience to cancer survivorship efforts and care as residual long-term or late effects of the cancer and its treatment begin to dominate a cancer patient's experience while health care utilization tends to decrease. The late and longterm effects relevant to cancer survivorship can be broadly categorized into medical effects, symptom burden, functional changes, and well-being. As can be seen in Table 2 , this definition encompasses acute, extended, and permanent phases of survivorship as Mullan proposed. This definition is also consistent with that proposed by LiveStrong which includes individuals living "with, through, and beyond cancer." Unique to this definition is an emphasis on the relevance of the post-primary treatment period to cancer survivorship initiatives.

\section{Going forward: How should we use these definitions?}

Having proposed definitions for cancer survivor and cancer survivorship, it is important to consider when the use of these definitions is appropriate. While they should be used to help aid decision making in research and practice, caution should be exercised when referring to these terms with patients. Survivorship is being increasingly viewed as an important topic for research and health care in Europe, but a stigma towards the term "cancer survivor" may still persist ${ }^{(51)}$. Going forward, as knowledge on cancer survival and the cancer patient's experience across the care trajectory increases, it will be important to revisit these definitions and modify them based on the latest evidence.

\section{REFERENCES}

1. Division of Cancer Prevention and Control, Centers for Disease Control and Prevention. Cancer Survivors: United States, 2007. Cancer Prevention and Control. 2014. Retrieved November 2, 2014, from http://www.cdc.gov/cancer/survivorship/ what_cdc_is_doing/research/survivors_article.htm

2. International Agency for Research on Cancer. GLOBOCAN 2012: Estimated Cancer Incidence, Mortality and Prevalence Worldwide in 2012. Retrieved November 2, 2014, from http://globocan.iarc.fr/Pages/ fact_sheets_cancer.aspx

3. Bell K, Ristovski-Slijepcevichhhh S. Cancer survivorship: why labels matter. J Clin Oncol 2013;31:409-11. Doi: 10.1200/ jco.2012.43.5891

4. Miller, K. D, Pandey, M, Jain, R, Mehta, R. (2015). Cancer Survivorship and Models of Survivorship Care: A Review. Am J Clin Oncol. Doi: 10.1097/ coc.0000000000000153

5. Leigh S. Defining our destiny. In Hoffman B, editor. A Cancer Survivor's Almanac: Charting the. Minneapolis, MN: Chronimed Publishing.9.261-71, 1996

6. Centers for Disease Control and Prevention, Department of Health and Human Services, \& Lance Armstrong Foundation. A National Action Plan for Cancer Survivorship: Advancing Public Health Strategies, 2004.p. 3-4.

7. Marcus A. Debate heats up on defining a cancer survivor. 2004. http://online.wsj.com/art icle/0,,SB108008897185563641,00.html

8. Rowland J. Survivorship research: Past, present, and future. In Ganz P, editor. Cancer survivorship: Today and tomorrow. New York, NY: Springer, 2007.p.28-42.

9. Twombly R. What's in a name: Who is a cancer survivor? J Natl Cancer Inst 2004;96: 1414-5. Doi: 10.1093/jnci/96.19.1414.

10. World Health Organization. Cancer control: knowledge into action - diagnosis 
and treatment $\mathrm{WHO}$ guide for effective programmes. Switzerland: World Health Organization, 2008.

11. Feuerstein M. Defining cancer survivorship. J Cancer Surviv 2007;1:5-7. Doi: 10.1007/s11764-006-0002-x

12. American Society of Clinical Oncology. About Cancer Survivorship. 2013. Retrieved November 2, 2014, from http://www. cancer.net/survivorship/about-cancer-survivorship

13. Doyle N. Cancer survivorship: evolutionary concept analysis. J Ad Nurs 2008; 62:499-509. Doi: 10.1111/j.13652648.2008.04617.x

14. Mullan F. Seasons of survival: reflections of a physician with cancer. $\mathrm{N}$ Engl J Med 1985;313:270-3. Doi: 10.1056/ nejm198507253130421

15. National Cancer Institute. Survivorship. NCI Dictionary of Cancer Terms. 2014.Retrieved November 2, 2014, from http://www. cancer.gov/dictionary?cdrid $=445089$

16. Office of Cancer Survivorship, National Cancer Institute. Definitions. 2014, May 30, 2014. Retrieved November 28, 2014, 2014, from http://cancercontrol.cancer. gov/ocs/statistics/definitions.html

17. Denlinger CS, Carlson RW, Are M, Baker KS, Davis E, Edge S.B, et al. Survivorship: Introduction and definition. Clinical practice guidelines in oncology. J Natl Compr Canc Netw 2004;12:34-45.

18. Martire LM. The "Relative" efficacy of involving family in psychosocial interventions for chronic illness: Are there added benefits to patients and family members? Fam Sys Health 2005;23:312-28. Doi:10.1037/1091-7527.23.3.312

19. Martire LM, Lustig AP, Schulz R, Miller GE, Helgeson VS. Is it beneficial to involve a family member? A meta-analysis of psychosocial interventions for chronic illness. Health Psychol 2004;23:599-611. Doi: 10.1037/0278-6133.23.6.599

20. Northouse L, Kershaw T, Mood D, Schafenacker A. Effects of a family interven- tion on the quality of life of women with recurrent breast cancer and their family caregivers. Psychooncology 2005;14:47891. Doi: 10.1002/pon.871

21. Hearn J, Higginson IJ. Do specialist paIliative care teams improve outcomes for cancer patients? A systematic literature review. Palliat Med 1998;12:317-32.

22. Martinez KA, Snyder CF, Malin JL, Dy SM. Patient-reported quality of care and pain severity in cancer. Palliat Support Care 2014;1-10. Doi: 10.1017/ s1478951514000777

23. Lobchuk MM, Degner LF. Symptom experiences: Perceptual accuracy between advanced-stage cancer patients and family caregivers in the home care setting. J Clin Oncol 2002;20:3495-507.

24. Clipp EC, George LK. Patients with cancer and their spouse caregivers. Perceptions of the illness experience. Cancer 1992;69:1074-9.

25. Phillips C, Hardcastle E, Desjardins L, Ruiz R, Bemis H, Arrington J, et al. Psychosocial health in survivors of adult versus childhood cancer. Paper presented at the American Society of Clinical Oncology Annual Meeting, Chicago, IL. Abstract retrieved from http://meetinglibrary.asco. org/content/118078-132, 2013

27. Siegel R, DeSantis C, Virgo K, Stein K, Mariotto A, Smith T, et al. Cancer treatment and survivorship statistics, 2012. CA Cancer J Clin 201,62:220-41. Doi: 10.3322/ caac. 21149

28. Children's Oncology Group. Long-term follow-up guidelines for survivors of childhood, adolescent, and young adult cancers (4.0 ed.), 2013.

29. Surveillance, epidemiology, and end results program. Age Standards for survival. Standard population data. 2014, from http://seer.cancer.gov/stdpopulations/survival.html

30. U.S. Department of Health and Human Services. Closing the gap: Research and care imperatives for adolescents and young 
adults with cancer. Report of the Adolescent and Young Adult Oncology Progress Review Group: U.S. Department of Health and Human Services, National Institutes of Health, National Cancer Institute, Livestrong Young Adult Alliance, 2006.

31. Bloom JR, Petersen, DM, Kang SH. Multidimensional quality of life among longterm (5+ years) adult cancer survivors. Psychooncology 2007;16:691-706. Doi: 10.1002/pon.1208

32. Stein KD, Syrjala KL, Andrykowski MA. Physical and psychological long-term and late effects of cancer. Cancer 2008;112(11 Suppl), 2577-92. Doi: 10.1002/cncr.23448

33. Harrison SE, Watson EK, Ward AM, Khan NF, Turner D, Adams E, et al. Primary health and supportive care needs of longterm cancer survivors: a questionnaire survey. J Clin Oncol 2011;29:2091-8. Doi: 10.1200/jco.2010.32.5167

34. Aaronson NK, Mattioli V, Minton O, Weis J, Johansen C, Dalton SO, et al Beyond treatment-Psychosocial and behavioural issues in cancer survivorship research and practice. EJC Supplements 2014;12:54-64. Doi: 10.1016/j.ejcsup.2014.03.005

35. Elliott J, Fallows A, Staetsky L, Smith PW, Foster CL, Maher EJ, Corner J. The health and well-being of cancer survivors in the UK: Findings from a population-based survey. Br J Cancer 2011;105 Suppl 1, S1120. Doi: 10.1038/bjc.2011.418

36. Harrington CB, Hansen JA, MoskowitzM, Todd BL, Feuerstein M. It's not over when it's over: long-term symptoms in cancer survivors-a systematic review. Int J Psychiatry Med 2010;40:163-81. Doi:10.2190/ PM.40.2.C

36. Mariotto $A B$, Rowland $J H$, Yabroff $K R$, Scoppa S, Hachey M, Ries L, Feuer EJ. Long-term survivors of childhood cancers in the United States. Cancer Epidemiol Biomarkers Prev 2009;18:1033-40. Doi:10.1158/1055-9965.epi-08-0988

37. Yu X. Epidemiology of cancer recurrence, second primary cancer, and comorbidi- ty among cancer survivors. In Feuerstein M, Ganz PA, editors. Health Services for Cancer Survivors: Research, Policy, and Practice. New York, NY: Springer2011. p. 277-97.

38. American Cancer Society. Cancer treatment and survivorship: Facts and figures 2014-2015. Atlanta, Georgia: American Cancer Society, 2014.

39. Fraumeni J, Curtis R, Edwards B, Tucker M. New malignancies among cancer survivors: SEER Cancer Registries, 1973-2000. (05-5302). Bethesda, Maryland: National Institutes of Health, 2006.

40. van der Heijden A, Witjes J. Recurrence, progression, and follow-up in non-muscleinvasive bladder cancer. European Urology Supplements 2008;8: 556-62.

41. Manfredi S, Bouvier AM, Lepage C, Hatem C, Dancourt V, Faivre J. Incidence and patterns of recurrence after resection for cure of colonic cancer in a well defined population. Br J Surg 2006;93:1115-22. Doi: 10.1002/bjs.5349

42. Figueredo A, Rumble RB, Maroun J, Earle CC, Cummings B, McLeod R, et al. Followup of patients with curatively resected colorectal cancer: A practice guideline. BMC Cancer 2003;3:26. Doi: 10.1186/14712407-3-26

43. Fisher B, Anderson S, Bryant J, Margolese RG, Deutsch M, Fisher ER, et al. Twentyyear follow-up of a randomized trial comparing total mastectomy, lumpectomy, and lumpectomy plus irradiation for the treatment of invasive breast cancer. N Engl J Med 2002;347:1233-241. Doi: 10.1056/ NEJMoa022152

44. Han M, Partin AW, Piantadosi S, Epstein JI, Walsh PC. Era specific biochemical recurence-free survival following radical prostatectomy for clinically localized prostate cancer. J Urol 2001;166:416-9.

45. Marrelli D, De Stefano A, de Manzoni G, Morgagni P, Di Leo A, Roviello F. Prediction of recurrence after radical surgery for gastric cancer: A scoring system obtained 
from a prospective multicenter study. Ann Surg 2005;241:247-55.

46. Begg A Predicting recurrence after radiotherapy in head and neck cancer. Semin Radiat Oncol 2012;22:108-18. Doi: 10.1016/j.semradonc.2011.12.002

47. Karaoglu I, van der Heijden AG, Witjes JA. The role of urine markers, white light cystoscopy and fluorescence cystoscopy in recurrence, progression and followup of non-muscle invasive bladder cancer. World J Urol 2014;32:651-9. Doi: 10.1007/s00345-013-1035-1

48. Zhang H, Ge T, Cui X, Hou Y, Ke C, Yang, $M$, et al. Prediction of advanced ovarian cancer recurrence by plasma metabolic profiling. Mol Biosyst 2014;11:516-21. Doi: 10.1039/c4mb00407h

49. Zhang Z, Chen D, Fenstermacher DA. Integrated analysis of independent gene expression microarray datasets improves the predictability of breast cancer outcome. BMC Genomics 2007;8:331. Doi: 10.1186/1471-2164-8-331

50. Engelhardt EG, Garvelink, MM, de Haes $\mathrm{JH}$, van der Hoeven JJ, Smets EM, Pieterse $\mathrm{AH}$, Stiggelbout AM. Predicting and communicating the risk of recurrence and death in women with early-stage breast cancer: A systematic review of risk prediction models. J Clin Oncol 2014;32:23850. Doi:10.1200/jco.2013.50.3417

51. Institute of Medicine. From cancer patient to cancer survivor: Lost in transition. In Hewitt M, Greenfield S, Stovall E, editors. Washington, D.C.: Committee on Cancer Survivorship: Improving Care and Quality of Life, Institute of Medicine and National Research Council, 2006

52. Armes J, Crowe M, Colbourne L, Morgan $\mathrm{H}$, Murrells T, Oakley C. et al. Patients' supportive care needs beyond the end of cancer treatment: A prospective, longitudinal survey. J Clin Oncol 2009; 27:6172-9. Doi: 10.1200/jco.2009.22.5151

53. Cheung WY, Neville BA, Cameron, DB, Cook EF, Earle CC. Comparisons of patient and physician expectations for cancer survivorship care. J Clin Oncol 2009;27:2489-95. Doi: 10.1200/ jco.2008.20.3232

54. Earle CC, Burstein HJ, Winer EP, Weeks C. Quality of non-breast cancer health maintenance among elderly breast cancer survivors. J Clin Oncol 2003;21:1447-51. Doi: 10.1200/jco.2003.03.060 